AGRARIS: Journal of Agribusiness and Rural Development Research

Vol. 6 No. 2: July-December 2020

Article History:

Submitted: November $21^{\text {st }}, 2020$

Accepted: December 3 ${ }^{\text {rd }}, 2020$
Kelly Kai Seng Wong ${ }^{1 *}$, Juwaidah Binti Sharifuddin1', Phuah Kit Teng², Wong Wang $\mathrm{Li}^{3}$, and Lai Kok Song ${ }^{4}$

${ }^{1}$ Department of Agribusiness and Bioresource Economics, Faculty of Agriculture, Universiti Putra Malaysia, Selangor, Malaysia.

2 Department of Marketing, Faculty of Accountancy, Finance and Business, Tunku Abdul Rahman University College, Kuala Lumpur, Malaysia.

${ }^{3}$ School of Economics and Management, Xiamen University Malaysia, Sepang, Malaysia.

4 Health Sciences Division, Abu Dhabi Women's College, Higher Colleges of Technology, Abu Dhabi, United Arab Emirates.

*) Correspondence email: kellywong@upm.edu.my

\title{
Impact of Urban Consumers' Food Consumption Behavior Towards Food Waste
}

DOI: https://doi.org/10.18196/agr.62100

\begin{abstract}
In this study, we aims to determine the factors that affect the consumers' food consumption behaviour and further to examine the impact of consumers' food consumption behaviour toward food waste in urban area. This study collected 400 questionnaires from the Klang Valley, Malaysia. The findings showed that there are three latent factors from the factor analysis which related to the negative food consumption behaviour, which were consumers' negative attitude on food demand, perceived behavioural control on food waste, and subjective norm. Multiple regression analysis showed that the negative food consumption attitude and perceived behavioural control on food waste have significant impact on the negative food consumption behaviour. Furthermore, the chi-square test showed that the percentage of food waste related to the difference level of negative consumption behaviour on food. Besides that, the Pearson Chi-square also showed that over demand for food and did not consume the food before expired date are highly significant associated with the number of food waste created by a household. In conclusion, consumers' proper planning on food consumption, cooking, and food deliver order playing a significant role to reduce food waste in Malaysia.
\end{abstract}

Keywords: Attitude, food consumption behavior, food waste, urban

\section{INTRODUCTION}

Food waste can be defined as all edible food materials that are produced for human consumption but are not eaten, whether it is lost or thrown away throughout the food supply stages (Chen et al., 2017). In Malaysia, food waste which includes left over and unconsumed food shows an increase at about $15 \%$ to 20\% during festive seasons (Jarjusey \& Chamhuri, 2017). Household and business outlets such as restaurant, resort and hotels are dumping over large quantities of food after their daily business activities. For example, during weddings, birthday party celebrations, and conferences, Aruna (2011) claims that Malaysian are throwing away up to 930 ton of unconsumed food daily and this is equivalent to $93,000 \mathrm{~kg}$ of rice per 
day. Thus, a reduction of food waste has important implication to support food sovereignty in the future in Malaysia.

Most global consumers are always confused by the labelling terms best before, use by date, use before, and consume by. According to Newsome et al. (2014), the difference within the date of labelling terms and its uses has led to huge food loss. This is because consumers and food manufacturers tend to misunderstand the labelling terms which indicates food product's expiry date. Besides that, food waste trends in Malaysia is worrisome. About 15,000 tonnes of food are wasted every day and about 3,000 tonnes are actually edible and should not be discarded (Jarjusey \& Chamhuri, 2017). Food waste makes up approximately $60 \%$ of municipal solid waste which are still categorised under the general problem of municipal solid waste management (Hassan et al., 2001). This soaring rate of food waste give harmful effects on the economy, environment and society as a whole.

The estimated food waste generated in Malaysia is totalling up to 9 million tonnes per year in 2011 (Table 1). The biggest source of food waste is household waste, and second is from the wet and night market. Third is waste from the food courts, restaurant and hotels then comes the food and beverage industries. The second last food waste contributor is from shopping mall and hypermarket, followed by institutions, schools and franchise restaurants.

TABLE 1. FOOD WASTE GENERATED IN MALAYSIA, 2011

\begin{tabular}{|c|c|c|}
\hline \multirow{2}{*}{ Sources } & \multicolumn{2}{|c|}{ Food waste } \\
\hline & Ton/day & Ton/year \\
\hline Household & 8,745 & $3,192,404$ \\
\hline Wet and night market & 5,592 & $2,040,929$ \\
\hline Food court/restaurant & 5,319 & $1,941,608$ \\
\hline Hotels & 1,568 & 572,284 \\
\hline Food and beverage industries & 854 & 311,564 \\
\hline Shopping malls & 298 & 108,678 \\
\hline Hypermarket & 291 & 106,288 \\
\hline Institutions & 55 & 26,962 \\
\hline Schools & 45 & 21,808 \\
\hline Fast food/ chain shops & 25 & 808 \\
\hline Total & 22,793 & $8,331,589$ \\
\hline
\end{tabular}

Source: Ministry of Housing and Local Government (MHLG), 2011

The total population in Malaysia in the fourth quarter of 2017 was 32.3 million. The population increased by 1.3 percent compared to fourth quarter in 2016. In 2017, urban population for Malaysia was $76.5 \%$ which amounted to 24.509 million. Urban population of Malaysia increased from $32 \%$ in 1968 to $76.5 \%$ in 2017 growing at an average annual rate of $1.78 \%$. Meanwhile the rural population was $23.5 \%$ which is 7.791 million (World meters, 2017) . Malaysia is now moving forward to become an urban nation as the number of urban populations continues to increase to almost $80 \%$ in 2017 as recorded.

Increasing rate of urban population provides a good business opportunity for food industry especially food delivery services. Hence, most of the urban family able to enjoy their variety food easily. In recent decades, women are more willing to participate in the working 
industry rather than to be a fulltime housewife. The changes in females' working behaviour are due to their education achievement, labour market demand, higher living costs in urban area, etc. Consequently, this phenomenon shows that the eating behaviour of a household has changed from the kitchen to the restaurant or food delivery service due to the limited time for food preparation. Besides, the cost of living in urban area sometimes force workers to spend more time in offices and have to sacrifice their family time for work; consequently, dining out is not an extraordinary thing for working parents. This lifestyle changes illustrate that the urban population is willing to work hard to gain more income and substitute their kitchen time to their working schedule (Ali \& Abdullah, 2012).

In Malaysia, the urban population has become the major contributor to more than 70 percent of the total waste generated (Budhiarta et al., 2012). Higher purchasing power in urban areas generate more opportunities for food service industry such as restaurant and online food services like food panda and Grab food. However, the convenient of food demand make consumers always over purchase food and consequently increase the amount of food waste. The urban population in Malaysia is now $76.5 \%$ of the total population. This large population encourage the rapid development of food system.

According to Chandon \& Wansink, (2012), consumers are easily influent by the marketing communications, and food-pricing strategies. Lower income group are predominantly affected by temporary price cuts and quantity discounts. Consequently, consumers over-purchased food and generate food waste. Besides that, most of the consumers did not store their food at the appropriate place and this can create higher volumes of food waste. Even though government taken an initiative to increase the awareness of society to reduce food waste especially in urban area, such as MySave food campaign in 2015. However, the effectiveness of this campaign on the food waste reduction is still low and most of the consumers responded to the market survey they are not aware of any campaign that has been organized by government to curb this menace (Jarjusey \& Chamhuri, 2017).

In summary, reduce food waste is crucial for urban area. The increasing food waste habit in urban society as a warning clock to the government as well as society towards food sovereignty. However, the society did not notice that the effort has been done by the government on food waste reduction. Furthermore, consumers' negative habit on food consumption such as did not keep their food in suitable place, misunderstand of labelling for best before and use before, etc are the main contribution on the market food waste. It is important to identify the factors related to the consumers' food consumption behaviour. Hence, the general objective in this study is to determine the factors affect the consumers' food consumption behaviour and further to examine the impact of consumers' food consumption behaviour toward food waste in urban area.

\section{Government's Food Waste Management Policy}

The National policy on Municipal solid waste management was generally recognized as the National Strategic plan (NSP) (Ghafar, 2017). This policy is one of the government initiatives to curb the food waste issues in Malaysia since food waste makes up to $60 \%$ on the municipal solid waste generated in Malaysia (Hassan et al., 2001). The National Strategic plan 
was formulated in 2002 and implemented in 2005. This policy key strategies are through their viable waste management. The sustainable waste management of this policy adopt the $3 \mathrm{Rs}$ concept which stands for reduce, reuse and recycle. This concept was done with the help of the proper technologies, equipment and facilities thus providing a viable and inclusive solid waste management service.

The first objective of waste management implemented under this National Strategic plan is to reduce waste. This done by efficient management of food waste resources at the stage of raw material usage, production, distribution, marketing and consumption (Ghafar, 2017). Then, the second objective to increase the number of sanitary landfills that are not polluting the environment (Ghafar, 2017). Furthermore, it also aims to reuse product and material (Ghafar, 2017). In addition, the objective is to recycle the reusable amount of waste that can still be used during source and waste collection separation stages (Ghafar, 2017). According to Moh \& Manaf (2014), the last objective is to implement intermediary management of waste and generate the value of waste.

The strategies formulated in this National Strategic plan aimed for solving the food waste issues in Malaysia through government support on data collection, setting up regulations and providing incentives. Then minimize the source of food waste. As a result, when sources of food waste decrease, the amount of food waste will be decreased, which also indicates less food waste to manage. Government has launched a centralized Food Waste Treatment Facilities to efficiently dispose the food waste and to minimize the impact of food waste in Malaysia.

Although, government in Malaysia carried out this National Strategic plan policy in 2005, the food waste issues in Malaysia is still not completely solved. Innovative strategies for proper management of the food wastes are still very limited and under-developed. A strategic plan particularly focused on food waste management is crucial. Therefore, creating possible solution to resolve the challenge of the entire waste management in Malaysia is a long-term plan

\section{RESEARCH METHOD}

This study attempts to investigate the impact of urban consumer food consumption pattern by adapting the Theory of Planned Behaviour by Ajzen (1991) and modifying theoretical framework by Russel et al. (2017). The modified framework is as shown in Figure 1 .

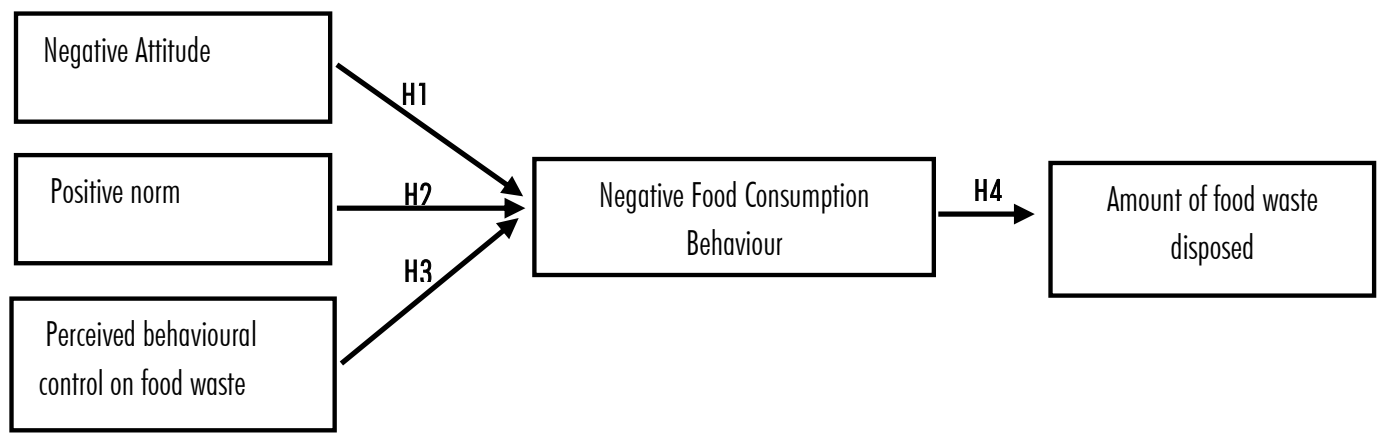

Sources: Adapted by theory of planned behaviour (Azjen, 1991) and modified from Russel et al. (2017)

FIGURE 1. FRAMEWORK ON FACTORS INFLUENCING THE AMOUNT OF FOOD WASTE DISPOSED 
There are 4 main hypotheses for the framework which are:

H1: Respondents' attitude towards food waste reduction will be positively related to the consumers' bad behaviour in consumption pattern;

H2: Subjective norm in relation to food waste will be positively related to consumers' bad behaviour in consumption pattern;

H3: Respondents' perceived behavioural control regarding food waste will be positively related to the consumer's bad behaviour in consumption pattern; and

$\mathrm{H} 4$ : Bad behaviour in consumption pattern have association with food wastage

\section{Questionnaire Design}

In this study, questionnaire was designed to examine the factors influence the consumers' consumption pattern and their food waste. The questionnaire distributed to 400 respondents with different age, gender, education level, occupation, income level, marital status and race. A self-administrated survey questionnaire was used as research method for this study. The questionnaire designed in six sections which are section $\mathrm{A}, \mathrm{B}, \mathrm{C}, \mathrm{D}, \mathrm{E}$, and $\mathrm{F}$.

Section A is to collect the information of respondents' socio-demographic profiles for example, age, gender, education level, occupation, income level, marital status and race. Section B related to the respondent's attitude to consumption pattern (lifestyle) that created food waste. Section $\mathrm{C}$ is about the respondent's perception of subjective norm that affect the consumption pattern (lifestyle). Section D related to the respondent's perceived behavioural control that leads to food waste. Section E is to analyse the respondent's lifestyles that leads to food waste. Finally, section F, was about the amount of food waste was disposed which measured in percentage of waste disposed based on food purchased. All questions in section $\mathrm{B}$ to section $\mathrm{F}$ were designed based on the 5-point Likert scale, which are $1=$ strongly disagree, $2=$ disagree, $3=$ neither agree nor disagree, $4=$ agree, and $5=$ strongly agree.

\section{Sampling Design}

This study was focusing on the consumers from Klang Valley area. Klang valley chosen as the sampling area because of its diversity of races and ethnics, and its population are consisting mostly of high-income group, which is suitable for this study's objective. The sampling design for this study is based on the cluster sampling. Subsequently, the region of Klang valley as the sample component was divided into six clusters, namely Kuala Lumpur, Putrajaya, Kajang, Sri Kembangan and Serdang. The targeted sample size for this study was 400 respondents and each cluster sampling location was assigned 80 questionnaires.

\section{RESULT AND DISCUSSIONS}

The 400 respondents' data were collected through the questionnaire survey and the overall demographic profile was summarized in Table 2. 
TABLE 2. SUMMARY OF RESPONDENTS' SOCIO DEMOGRAPHIC PROFILE

\begin{tabular}{|c|c|c|c|}
\hline \multicolumn{2}{|l|}{ Profiles } & Frequency (N) & Percentage (\%) \\
\hline \multirow[t]{2}{*}{ GENDER } & Male & 220 & 55.0 \\
\hline & Female & 180 & 45.0 \\
\hline \multirow[t]{6}{*}{ AGE } & $18-24$ years & 79 & 19.75 \\
\hline & $25-34$ years & 135 & 33.75 \\
\hline & $35-44$ years & 103 & 25.75 \\
\hline & $45-54$ years & 66 & 16.5 \\
\hline & $55-64$ years & 16 & 4.0 \\
\hline & 65 years and above & 1 & 0.25 \\
\hline \multirow[t]{4}{*}{ RACE } & Malay & 249 & 62.3 \\
\hline & Chinese & 92 & 23.0 \\
\hline & Indian & 59 & 14.8 \\
\hline & Others & 0 & 0 \\
\hline \multirow[t]{5}{*}{ RELIGION } & Islam & 249 & 62.3 \\
\hline & Buddha & 91 & 22.8 \\
\hline & Hindu & 58 & 14.5 \\
\hline & Christian & 2 & 0.5 \\
\hline & Others & 0 & 0 \\
\hline \multirow[t]{4}{*}{ ANCESTRY } & Malay & 249 & 62.3 \\
\hline & Chinese & 91 & 23.0 \\
\hline & Hindu & 59 & 14.8 \\
\hline & Others & 0 & 0 \\
\hline \multirow[t]{5}{*}{ DISTRICT } & Serdang & 89 & 22.3 \\
\hline & Seri Kembangan & 80 & 20.0 \\
\hline & Kajang & 79 & 19.8 \\
\hline & Putrajaya & 68 & 17.0 \\
\hline & Kuala Lumpur & 84 & 21.0 \\
\hline \multirow[t]{3}{*}{ MARITAL STATUS } & Single & 164 & 41.0 \\
\hline & Married & 236 & 59.0 \\
\hline & Others & 0 & 0 \\
\hline \multirow[t]{8}{*}{ EDUCATION LEVEL } & Primary school & 0 & 0 \\
\hline & Secondary school & 46 & 11.5 \\
\hline & Certificate Level & 56 & 14.0 \\
\hline & Diploma & 104 & 26.0 \\
\hline & Bachelor & 173 & 43.3 \\
\hline & Master & 20 & 5.0 \\
\hline & Ph.D. & 1 & 0.3 \\
\hline & Others & 0 & 0 \\
\hline \multirow[t]{5}{*}{ OCCUPATION } & Government sector & 101 & 25.3 \\
\hline & Private sector & 165 & 41.3 \\
\hline & Self-employ & 65 & 16.3 \\
\hline & Student & 68 & 17.0 \\
\hline & Others & 1 & 0.3 \\
\hline \multirow[t]{5}{*}{ MONTHLY INCOME } & RM 0 - RM 1000 & 70 & 17.5 \\
\hline & RM1001- RM3000 & 124 & 31.0 \\
\hline & RM3001-RM5000 & 142 & 35.5 \\
\hline & RM5001-RM8000 & 60 & 15.0 \\
\hline & $>$ RM8000 & 4 & 1 \\
\hline
\end{tabular}


Table 3 indicates that three latent factors from the factor analysis which related to the negative food consumption behaviour, which were consumers' negative attitude on food demand, perceived behavioural control on food waste, and subjective norm. These three factors showed about $81.05 \%$ of the variation of the data are explained by these three factors.

TABLE 3. FACTORS INFLUENT URBAN CONSUMER FOOD CONSUMPTION PATTERN TOWARDS FOOD WASTE

\begin{tabular}{lccc}
\hline & \multicolumn{3}{c}{ Factor } \\
\cline { 2 - 4 } & 1 & 2 & 3 \\
\hline consumers' negative attitude on food demand & & \\
I am not worried about the amount of food that is wasted in my household & .914 & \\
I am not worried about the cost of food that I throw away. & .899 & \\
I am not worried about the amount of food that I have thrown away. & .809 & \\
Perceived Behavioural Control on food waste & & .891 \\
I could not control myself to waste food. & & .883 \\
It is difficult for me to reduce my food waste. & & .780 & \\
It is difficult for me to have a list of what I need before purchase food from market. & & & .805 \\
Positive norm & & & .907 \\
I will reduce food waste, if the people who are important to me completely supported. & 3.902 & 1.322 & 1.261 \\
Most people who are important to me think that reducing food waste is good. & 48.733 & 16.521 & 15.760 \\
\hline Eigenvalue & 48.733 & 65.294 & 81.054 \\
\% of total variance & & \\
Total cumulative Variance & & \\
\hline
\end{tabular}

Note: Extraction Method: Principal Component Analysis. Rotation Method: Varimax with Kaiser Normalization.

The first factor is about the consumers' negative attitude on the food demand. Most of the respondents did not worried about the amount and the cost of food waste and this factor explained the total variance about $48.73 \%$ which are the important factor related to the negative food consumption behaviour.

The second factor is represented the perceived behavioural control on food waste and explained in $16.52 \%$ of the overall dataset. There were three questions categorized in this factor; i.e. (i) the respondents are difficult to control themselves to waste food; (ii) the respondents are feeling difficult to reduce the amount of food waste; and (iii) the respondents are unable to prepare the food list before they purchase food from grocery shops.

The third factor is labelled as positive norm which is expected to have a negative impact on the negative food consumption behaviour. This factor was explained by two questions, i.e. the respondent will reduce food waste when supported by the people who are important to him/her, and the people who are important to him/her have a positive perception on the food waste reduction.

Multiple regression analysis was used to investigate the most influential factor towards consumer's negative food consumption behaviour. The estimated result (Table 4) showed that the negative food consumption attitude and perceived behavioural control on food waste have significant impact on the negative food consumption behaviour. The positive coefficient of negative food consumption attitude (0.052) indicates that if the respondents are not worried about the volume and cost of food waste then the consumers will easily to excess demand for food and thrown the good condition food away when the tastes of food is not good. Besides 
that, perceive behavioural control on food waste also showed positive coefficient towards the negative food consumption behaviour. This implied that if the respondents are not able to control themselves to waste food, then the food waste will increase.

TABLE 4. SUMMARY OF NEGATIVE FOOD CONSUMPTION BEHAVIOUR REGRESSION MODEL

\begin{tabular}{lcccc}
\hline & Coefficient & Std. Error & t-stat & Sig \\
\hline Constant & 3.747 & .024 & 153.524 & $0.000^{* * *}$ \\
Negative food consumption attitude & 0.052 & 0.024 & 2.115 & $0.035^{* *}$ \\
Perceived behavioural control on food waste & 0.289 & 0.024 & 11.806 & $0.000^{* * *}$ \\
Positive norm & -0.001 & 0.024 & 0.045 & 0.964 \\
\hline
\end{tabular}

R square : 0.266

Adjusted R Square : 0.261

Dependent Variable : Consumption pattern

Note: ${ }^{* * *},{ }^{* *}$, and ${ }^{*}$ denotes as significant at $1 \%, 5 \%$ and $10 \%$ significance level, respectively.

In this survey, respondent was asked a question of "How many percent of food was wasted by you during the latest month?". This question was aimed to estimate food waste from a household. Respondents showed that the percentage of food waste related to the difference level of negative consumption behaviour on food. For example, amount of food waste correlated with the taste of food (Table 5). If the respondent dislikes the food tastes, then they will throw it away. Even the food is still in a good condition. The Pearson Chi-square also showed that over demand for food and did not consume the food before expire date are highly significant associated with the number of food waste created by a household.

\begin{tabular}{llllll}
\multicolumn{4}{l}{ TABLE 5. SUMMARY OF CHI-SQUARE TEST ON NEGATIVE FOOD CONSUMPTION BEHAVIOUR WITH HOUSEHOLD'S FOOD WASTE } \\
\hline Bad behaviour in food consumption pattern & $\begin{array}{l}\text { Pearson Chi- } \\
\text { square value }\end{array}$ & df & Significant & Decision \\
\hline I throw away food because the taste is not good & 36.555 & 16 & $0.002^{* * *}$ & Reject Ho \\
$\begin{array}{l}\text { I often forget the food that are stored in my refrigerator } \\
\text { until it is spoiled }\end{array}$ & 44.791 & 16 & $0.000^{* * *}$ & Reject Ho \\
\hline
\end{tabular}

Note: ${ }^{* * *},{ }^{* *}$, and ${ }^{*}$ denotes as significant at $1 \%, 5 \%$ and $10 \%$ significance level, respectively.

\section{CONCLUSIONS}

In Malaysia, rapid growth of food waste should take it seriously and needs to reduce it immediately. The grave problem of food waste usually related to the consumers' bad food demand habit such as excess-buying, inadequate storage for food, and luxury lifestyle. As estimated by Solid Waste and Public Cleansing Corporation (SWCorp), there are about 3,330 tonnes of daily food wasted from the households and food industry. In order to reduce the food waste, household's food demand habit should be changed.

In this study, household's bad attitude on food demand was the main factor explained the household's bad consumption habit. For example, if the household unappreciated the food value then they will easily throw away the food. Besides that, negative behaviour on food consumption highly related to the personal perceive control on food waste. When the respondent uncontrolled themselves to waste food easily then they will just throw away their food. Even the food is still good condition and safely consume. Furthermore, when the 
respondent feels difficult to reduce food waste and did not have a proper planning before buying and cooking, food waste can be increased due to the inadequate storage of food. However, the bad habit on food demand can be changed through the friend or family's advice and support on food waste reduction.

In conclusion, consumers playing a significant role to reduce food waste in Malaysia. Environment support can help the respondents to reduce food waste such as government campaign and advertise the important of food waste reduction in social media are important to change the bad habit on food consumption. Besides that, proper planning on food consumption, cooking, and food deliver order also important to reduce the food waste from market.

\section{ACKNOWLEDGEMENTS}

This work was supported and funded by the Ministry of Higher Education (MOHE) Malaysia for the award of Fundamental Research Grant Scheme, code project FRGS/1/2018/SS08/UPM/02/2.

\section{REFERENCES}

Ajzen, I., (1991). The theory of planned behaviour. Organizational Behaviour. Human Decision Process, 50 (2), 179-211.

Ali, N. \& Abdullah, M.A. (2012). The Food Consumption and Eating Behaviour of Malaysian Urbanites: Issues and Concerns. Malaysia Journal of Society and Space, 8(6), 157 165.

Aruna P. (2011). 930 Tonnes of food being thrown away every day. The Star online (date: 10 June 2011). Retrieved: https://www.thestar.com.my/news/nation/2011/06/10/930tonnes-of-food-being-thrown-away-every-day/.

Budhiarta, I., Siwar, C. \& Basri, H. (2012). Current Status of Municipal Solid Waste Generation in Malaysia. International journal on Advanced Science Engineering Information Technology, 2(2), $16-21$.

Chandon, P, and Wansink, B (2012). Does Food Marketing Need to Make Us Fat? A Review and Solutions. Nutrition Reviews, 70 (10), 571-93.

Chen, H., Jiang, W., Yang, Y., Yang, Y., \& Man, X. (2017). State of the Art on Food Waste Reseabibliometrics Study from 1997 to 2014. Journal of Cleaner Production, 140, 840-846.

Ghafar, S.W.A (2017). Food Waste in Malaysia: Trends, Current Practices and Key Challenges. FFTC Agricultural Policy Articles. Retrieved: http://ap.fftc.agnet.org/ap_db.php?id=774\& print=1.

Hassan, M. N., Chong, T. L., Rahman, M., Salleh, M. N., Zakaria, Z., \& Awang, M. (2001). Solid waste management in Southeast Asian countries with special attention to Malaysia. Paper presented at the 8th International Waste Management and Landfill Symposium (pp. 1-5), Environmental Sanitary Engineering Centre, Cagliari, Italy. 
Jarjusey, F. \& Chamhuri, N. (2017). Consumers' Awareness and Knowledge about Food Waste in Selangor, Malaysia. International Journal of Business and Economic Affairs, 2(2), $91-97$.

Moh, Y. C. \& Manaf, L. A. (2014). Overview of Household Solid Waste Recycling Policy Status and Challenges in Malaysia. Resources, Conversation and Recycling, 82, 50-61.

Newsome, R., Balestrini, C. G., Baum, M. D., Corby, J., Fish-er, W., Goodburn, K., Labuza, T. P., Prince, G., Thesmar, H. S., \& Yiannas, F. (2014). Applications and Perceptions of Date Labeling of Food. Compr. Rev. Food Sci. Food Saf., 13, 745-769.

Russell, S.V., Young, C.W., Unsworth, K.L. \& Robinson, C. (2017). Bringing Habits and Emotions Into Food Waste Behaviour. Resources, Conservation and Recycling, 125, 107-114. 